\title{
MORPHOMETRICS AND ADAPTATIVES ASPECTS IN AFRICANIZED HONEYBEES (Apis mellifera)
}

\author{
OLIVEIRA-JR, W. P., BRANDEBURGO, M. A. M. and MARCOLINO, M. T. \\ Instituto de Genética e Bioquímica, Universidade Federal de Uberlândia, C.P. 593, Campus Unuarania, \\ Bloco 2E, Sala 20, CEP 38400-902, Uberlândia, MG, Brazil \\ Correspondence to: Malcon A. M. Brandeburgo, Instituto de Genética e Bioquímica, Universidade Federal de \\ Uberlândia, C.P. 593, Campus Unuarania, Bloco 2E, Sala 20, CEP 38400-902, Uberlândia, MG, Brazil \\ Received April 9, 1999 - Accepted July 1, 1999 - Distributed May 31, 2000
}

\begin{abstract}
The introduction of the African bees (Apis mellifera scutelata) in Brazil and their expansion in the American Continent created the opportunity to study the process of species adaptation in a new environment. In that process, within intra-specific variability, normalising selection can favour individuals that present a better adaptative morphology and they will constitute the most frequent type found in the population. To test that hypothesis morphometric analyses in samples of colonies of africanized bees and in samples of the populations were performed. The development of the colonies was also evaluated in terms of the amount of their brood, honey and pollen. Analysis of the data indicates that more developed colonies are formed by individuals closer to the population average with concerning morphological traits.
\end{abstract}

Key words: africanized honeybees, adaptation, morphologic characters.

\section{RESUMO}

\section{Aspectos morfométricos e adaptativos em abelhas africanizadas (Apis mellifera)}

A introdução das abelhas africanas (Apis mellifera scutelata) no Brasil e sua expansão pelo Continente Americano criou a oportunidade de se estudar o processo de adaptação de uma espécie em um novo ambiente. Nesse processo, dentro da variabilidade intra-específica, a seleção normalizante pode favorecer os indivíduos que apresentam uma morfologia mais adaptativa, os quais constituirão o tipo mais freqüente encontrado na população. Para testar essa hipótese foram feitas análises morfométricas em amostras de colônias de abelhas africanizadas e em amostras da população. Também foi avaliado o desenvolvimento das colônias em termos da quantidade de cria, mel e pólen. A análise dos dados mostrou que as colônias que mais se desenvolveram são formadas por indivíduos mais próximos da média da população quanto às características morfológicas.

Palavras-chave: abelhas africanizadas, adaptação, caracteres morfológicos.

\section{INTRODUCTION}

The africanized bees (Apis mellifera scutelata) were introduced in Brazil in 1956 (Kerr, 1967; Pardo, 1979), occupying starting from there South America, Central and, also, it leaves of North America.

That occupation process, that happened due to adaptation and reproductive efficiency of the africanized bees (Rinderer et al., 1993), it turned them an important biological material for the studies related with the adaptive processes. It is interesting to observe that to the long of those processes the natural selection models the individuals around a medium phenotype, which characterizes the species or the sub-species. Thus, a relationship is verified between morphologic characters and the adaptation. 
Several works with Apis mellifera involving morphologic characters showed that there is strong influence of the environment in the morphology of the same ones (Eischen et al., 1982; Milne \& Friars, 1984; Milne et al., 1986). One of these characters is the corbiculae, whose area and length meet positively correlated with the productivity (Eischen et al., 1982; Milne \& Pries, 1984; Kolmer \& Sam, 1991). In agreement with Milne et al. (1986), the bees that present larger corbiculae can carry more pollen and, in that way, feed larger amount of brood, resulting in the increase of the colony and consequently in larger honey production. Also have been obtained correlation between the size of the bees and the productivity of the colonies (Waddington, 1989).

Other very studied characters are the antennas and the wings. Mattu \& Verma (1983) verified that the total length of the antenna, in Apis cerana indica, increases in agreement with the increase of the altitude in areas of Himalayan. Meixner et al. (1989), studying Apis mellifera scutellata and A. m. monticola, in the areas of Kilimanjaro, also found positive correlation between the length of the wing and the altitude. Thus, such correlations can indicate the importance of the morphologic characteristics in the adaptation of the individuals to the environment (Singh, 1990). In the work of Kolmer \& Sam (1991) was presented the hypothesis that the characters more adapted to a certain habitat are selected, in an evolutionary way and, independently, for the circumstances of the environment.

The phenotypic correlation can supply information, so much at evolutionary as genetic level, concerning the morphologic evolution of the organisms in study. If the correlation among two characteristics is significant, it can imply in some genetic control common to both studied characters (Milne, 1981).

Thus, only those individuals that approach of the average of the population are that they would have larger survival chance, that is to say, they would show larger adaptability degree (Mettler \& Gregg, 1973; Mayr, 1977).

Our study was accomplished in the Campus Umuarama of the Federal University of Uberlândia, MG, Brazil, where we analyzed the morphology of bees africanized workers. The objective was to verify if most of the individuals of a certain population, adapted to a specific place, come inside of a morphometric standard as a consequence of the normalizing selection.

\section{MATERIAL AND METHODS}

Eight colonies of africanized bees were used, which were installed in boxes type nuclei $(46.5 \mathrm{x}$ $18.5 \times 24 \mathrm{~cm}$ ) painted with different colors to facilitate the identification. In each nucleus was placed four combs and an internal feeder of the type Doolitle (Wiese, 1995; Puttkammer, 1994).

The hives were obtained in the apiary of Federal University of Uberlândia, starting from eight beehives already installed. Of each colony they were retired four combs, three contend eggs, brood, pupae, young and adult bees and one contend honey. This combs, was inspected to avoid the retreat of the queen, they were transferred for the nuclei, which were transported to the Campus Umuarama - Federal University of Uberlândia.

Starting from the installation, the nuclei were supervised and fed, to promote the invigoration of the colonies. The food composed with $60 \%$ of sugar and $40 \%$ of water (Wiese, 1995; Puttkammer, 1994) it was weekly offered until the stabilization of the colonies. That stabilization was defined by the production of a queen and for the increase in the number of bees in each colony. Thus, a stabilized colony presented great number of individuals, that consumed the whole offered food quickly and, consequently, they filled the combs with pollen, honey and brood. In the period of observation and data collects (August-October/ 1996) the beehives were not fed, to take its adaptation capacity.

\section{Samples morphometry}

The samples were composed of twenty workers (foragers) of each colony, collected in the entrance of the experimental beehives. In the same way, samples were collected in others four colonies, captured in the area in the Campus Umuarama, and samples of beehives of three other places distant between 8 and $10 \mathrm{Km}$ of Uberlândia.

Those samples were droughts in stove to 50 ${ }^{\circ} \mathrm{C}$, for twenty-four hours (Eischen et al., 1982). Each individual was weighed separately in an analytic scale Precision AA250 for obtaining of the dry weight. They were prepared sheets contends 
the wings (forewing and hindwing) and being these retired structures on the right side. The length and the width of the wings and the total length of the antenna were taken with the use of a glass magnifying Leica, I model Wild M3C (Heerbrugg Switzerland), equipped with ocular contends millimetrical ruler, regulated in increase of ten times, for the wings, and of sixteen times for the antenna. After the measure of the wings and of the antenna, the head and the composed eye were measured (width and length). To do this, the individuals were fastened with pins inserted in the thorax, having been used the increase of sixteen times.

\section{Comb mappeament}

To accompany the development of the colonies in the months of August, September and October/1996 a total of three mappeaments was accomplished. Those were accomplished with the use of a modified device of the model used by Brandeburgo \& Gonçalves (1989) where the comb was divided in three quadrants, which were subdivided in five subquadrants. Each subquadrant was worth $20 \%$ of the total quadrant and the numbers $0,1,2,3,4$ and 5 to represent that, respectively, $0 \%, 20 \%, 40 \%, 60 \%, 80 \%$ and $100 \%$ of the quadrant contained honey, brood, or pollen.

The percentages of brood, honey or pollen of the three quadrants were added and of there it was obtained the medium value of fulfilling in one on the sides of the comb (side A), corresponding to each product. The same was made with the other side (side B) and the obtained values were added to the on the side A to obtain the total value of fulfilling of the comb. We repeated that procedure with the other combs of the colony and the sum of the all values supplied a relative medium value of amount to each product (honey, brood and pollen) in each nucleus. Starting from the medium value regarding to the sum of the three mappeaments accomplished during the experiment, it was possible to characterize the development of the colonies.

\section{Data processing}

The data of the mensurations and of the mappeaments were analyzed with the aid of the program Statistic 4.5 (StatiSoft, Inc., 1993). The averages of the areas with honey, brood and pollen were calculated in the three mappeaments accomplished with the experimental colonies. The data of two main groups of bees were also analyzed, a composed by the total sample of colonies $(\mathrm{N}=$ 300) and another for a portion of that, formed by the samples of the eight experimental colonies $(\mathrm{N}=$ 160). The medium values of the measures of each morphologic characteristic for the samples of all the colonies (population) and for each experimental colony were obtained. Soon after, the difference was calculated among the averages of the morphologic characteristics of each nucleus and of the total population. That was made to evidence how each nucleus differed, in relation to each characteristic, of the medium value (pattern) of the total population.

To follow, it was used an index W (Brandeburgo, 1995) with the objective of balancing the relative value of the different morphologic characteristics, because the measures were obtained being used different increases in the glass magnifying due to the great size differences among some characteristics. With the index, all the characteristics have proportional representation in the total group of the phenotype. To explain the way as the index $\mathrm{W}$ was calculated we take as example characteristic B (length of the forewing, Table 4). Being added the values of the relative differences to characteristic B obtained for the different colonies, independently of the mathematical sign, are obtained the value of 0.54 . We verified that the value of 0.03 , presented by the colony 1 for characteristic B, represents $5.56 \%$ of the total value. Those percentiles ones were calculated for all the characteristics (Table 5). The percentile ones obtained for each colony were added and divided by the total number of characteristics (10), being obtained the percentile medium that corresponds to the index $\mathrm{W}$, which indicates as each nucleus approaches of the medium value of the population $(\mathrm{W}=0)$.

The other analysis was to estimate of the correlation index among the characteristics. The coefficient of Pearson was used with significance level $\mathrm{p}<0.05$. The correlation indexes among the morphologic characteristics in the total population $(\mathrm{N}=300)$ and the correlation indexes among the area of brood, honey and pollen and the morphologic characteristics were calculated. In that last estimate the values of the averages of each nucleus were used $(\mathrm{N}=8)$, that represented a total group of 160 individuals. 


\section{RESULTS}

A clear development difference was observed among the colonies, because the same ones are in growing order with relationship to its development (Table 1), considering that the largest occupation of the combs, with brood, honey and pollen, evidence a larger degree of environmental adaptation. We can observe a group of colonies with smaller development (1,2 and 3) and another with larger development (6, 7 e 8$)$ and, probably, more adapted. This is an evidence of the relationships between the morphologic characteristics and the adaptation.

The averages of each morphologic characteristic, so much of the colonies as of the population, are represented in the Tables 2 and 3, respectively. The Table 4 show the mathematical differences among the medium value presented by the morphologic characteristics in each colonies (Table 2 ) and the medium value of the total population regarding each characteristic (Table 3 ).

TABLE 1

Medium occupation of the combs with brood, honey and pollen in each colony.

\begin{tabular}{|c|c|c|c|c|}
\hline \multirow{2}{*}{ Colony N. } & \multicolumn{4}{|c|}{ Occupation (\%) } \\
\cline { 2 - 5 } & Brood & Honey & Pollen & Total \\
\hline 1 & 4.44 & 2.67 & 0 & 7.11 \\
\hline 2 & 8.89 & 2.67 & 0.89 & 12.45 \\
\hline 3 & 19.33 & 3.56 & 1.18 & 24.07 \\
\hline 4 & 16.67 & 9.33 & 0.89 & 33.12 \\
\hline 5 & 29.11 & 1.56 & 2.45 & 38.01 \\
\hline 6 & 29.78 & 7.56 & 0.67 & 47.34 \\
\hline 7 & 36.45 & 9.11 & 1.78 & 47.55 \\
\hline 8 & 32.89 & 13.33 & 1.33 & \\
\hline
\end{tabular}

*The Total represents the percentage of combs filled in each colony.

TABLE 2

Averages presented by the morphologic characteristics in each colony.

\begin{tabular}{|c|c|c|c|c|c|c|c|c|c|c|}
\hline \multirow{2}{*}{ Col. N. } & \multicolumn{10}{|c|}{ Characteristics } \\
\hline & $\mathbf{A}$ & B & C & D & $\mathbf{E}$ & $\mathbf{F}$ & $\mathbf{G}$ & $\mathbf{H}$ & I & $\mathbf{J}$ \\
\hline 1 & .0205 & 8.74 & 2.99 & 6.04 & 1.74 & 4.16 & 3.42 & 3.75 & 2.37 & 0.97 \\
\hline 2 & .0203 & 8.69 & 2.94 & 6.03 & 1.67 & 4.19 & 3.44 & 3.74 & 2.36 & 1.03 \\
\hline 3 & .0197 & 8.61 & 2.93 & 5.97 & 1.68 & 4.17 & 3.31 & 3.71 & 2.35 & 1.01 \\
\hline 4 & .0201 & 8.71 & 2.98 & 6.04 & 1.71 & 4.22 & 3.33 & 3.67 & 2.33 & 1.03 \\
\hline 5 & .0213 & 8.53 & 3.01 & 5.95 & 1.71 & 4.2 & 3.34 & 3.66 & 2.35 & 1.03 \\
\hline 6 & .0195 & 8.64 & 2.99 & 6.07 & 1.72 & 4.27 & 3.36 & 3.55 & 2.38 & 1.02 \\
\hline 7 & .0187 & 8.64 & 3.04 & 6.01 & 1.74 & 4.29 & 3.4 & 3.74 & 2.39 & 1.01 \\
\hline 8 & .0215 & 8.78 & 3.04 & 6.17 & 1.74 & 4.25 & 3.36 & 3.72 & 2.39 & 1.03 \\
\hline
\end{tabular}

Characteristcs: $\mathrm{A}=$ dry weigh (g.); $\mathrm{B}=$ length of the forewing; $\mathrm{C}=$ width of the forewing; $\mathrm{D}=$ length of the hindwing; $\mathrm{E}=$ width of the hindwing; $\mathrm{F}=$ total length of the antenna; $\mathrm{G}=$ length of the head; $\mathrm{H}=$ width of the head; $\mathrm{I}=$ length of the composed eye; $\mathrm{J}=$ width of the composed eye. Characteristics $\mathrm{B}$ and $\mathrm{J}$ is represented in $\mathrm{mm}$. 
TABLE 3

Averages of each morphologic characteristic analyzed in the population $(\mathbf{N}=\mathbf{3 0 0})$.

\begin{tabular}{|c|c|c|c|c|c|c|c|c|c|c|}
\hline & \multicolumn{10}{|c|}{ CHARACTERITICS } \\
\cline { 2 - 12 } & $\mathbf{A}$ & $\mathbf{B}$ & $\mathbf{C}$ & $\mathbf{D}$ & $\mathbf{E}$ & $\mathbf{F}$ & $\mathbf{G}$ & $\mathbf{H}$ & $\mathbf{I}$ & J \\
\cline { 2 - 12 } & .0200 & 8.71 & 3.01 & 6.08 & 1.72 & 4.24 & 3.38 & 3.7 & 2.38 & 1.01 \\
\hline
\end{tabular}

Characteristcs: $\mathrm{A}=$ dry weigh (g.); $\mathrm{B}=$ length of the forewing; $\mathrm{C}=$ width of the forewing; $\mathrm{D}=$ length of the hindwing; $\mathrm{E}=$ width of the hindwing; $F=$ total length of the antenna; $G=$ length of the head; $H=$ width of the head; $I=$ length of the composed eye; $\mathrm{J}=$ width of the composed eye. Characteristics $\mathrm{B}$ and $\mathrm{J}$ is represented in $\mathrm{mm}$.

In the Table 4 we can verify that the colony 8 , more developed in terms of occupation of the combs, presented positive differences in nine of the ten analyzed characteristics, while the other colony varied to each characteristic. That shows that the colony 8 presented larger bees than the average of the total population in those nine characters.

To leave of those results, the index $\mathrm{W}$ was calculated (Table 5). In that table, we can observe that the colonies 6,7 , and 8 were the ones that they presented smaller values of $\mathrm{W}$ and, being like this, they presented phenotypes with smaller differences in relation to the average of the population. On the other hand, the nuclei 1, 2 and 3 presented larger values of $\mathrm{W}$. Such observations showed, at a phenotype level, that the three more developed colonies (more adapted) were closer of the average, while the three less developed (less adapted) were more morphologically distant of the average of the population. Similar results were obtained by Brandeburgo (1995) working with africanized bees of the area of Ribeirão Preto, SP, Brazil.

The colonies with intermediary development (4 and 5) presented, however, a less defined situation, being the more developed (colony 5) more distant of the average that the colony 4 , less developed. In terms of the phenotypic aspects we can observe a larger proximity of the group of colonies more developed to the average of the population, evidences an effect of the normalizing selection.

Still in the Table 5, that selection is evidenced particularly for some characters. Like this being, the colonies 6,7 and 8 , the more developed, presented for the characters width of the forewing $(\mathrm{C})$, width of the hindwing (E), length of the antenna (F) length of the head $(\mathrm{G})$, and length of composed eye (I), closer values of the medium value of the population.

The colony 4 was not among the more developed, although it presented a close value to the general medium value $(\mathrm{W}=9.86)$. That took us to compare it with the developed colonies (6, 7 and 8 ) and we verified that the colony 4 presented a smaller total length of the antenna (Table 5, characteristic F). This characteristic can have been influencing in its adaptive capacity, once, that morphologic characteristic showed a correlation significantly positive with the areas of brood and honey (Table 6). We believed that is due to the fact that the antenna is important for the bee, because the sensorial organs are located in this structure and it is important for food identification and location. Already the other characteristics like the dry weight, wings, head and composed eye (Table 6) didn't show significant correlation with the areas of brood, honey and pollen, except the length of the hindwing, that presented positive correlation with the honey area.

Many other morphologic characteristics came significantly correlated to each other (Table 7), in particular the width of the wing with the other characteristics. This show a tendency to the establishment of a balanced phenotype, that is to say a phenotypic harmonious group, which is favored by the natural selection (Mayr, 1977). It can also evidence that genetic correlation exists among those characterses (Riedl, 1978 in Futuyma, 1992), which would form an integrated group. The evolution and expression of those characterses will happen in an integrated way.

\section{DISCUSSION}

Starting from the obtained results we verified that the increase of the areas in the comb with brood, honey and pollen can be an adaptation indicator, supplying information about the performance of the natural selection on the colonies of bees. 
TABLE 4

Mathematical differences between the average of the morphologic characteristics of each nucleus and the average of the analyzed total population.

\begin{tabular}{|c|c|c|c|c|c|c|c|c|c|c|}
\hline \multirow{2}{*}{ Col. N. } & \multicolumn{10}{|c|}{ Characteristics } \\
\cline { 2 - 13 } & $\mathbf{A}$ & $\mathbf{B}$ & $\mathbf{C}$ & $\mathbf{D}$ & $\mathbf{E}$ & $\mathbf{F}$ & $\mathbf{G}$ & $\mathbf{H}$ & \multicolumn{1}{|c|}{ I } & $\mathbf{J}$ \\
\hline 1 & .0005 & .03 & -.02 & -.04 & .02 & -.08 & .04 & .05 & -.01 & -.04 \\
\hline 2 & .0003 & -.02 & -.07 & -.05 & -.05 & -.05 & .06 & .04 & -.02 & .02 \\
\hline 3 & -.0003 & -.10 & -.08 & -.11 & -.04 & -.07 & -.07 & .01 & -.03 & 0 \\
\hline 4 & .0001 & 0 & -.02 & -.04 & -.01 & -.02 & -.05 & -.03 & -.05 & .02 \\
\hline 5 & .0013 & -.18 & 0 & -.13 & -.01 & -.04 & -.04 & -.04 & -.03 & .02 \\
\hline 6 & -.0005 & -.07 & -.01 & -.01 & 0 & .03 & -.02 & -.15 & 0 & .01 \\
\hline 7 & -.0013 & -.07 & .03 & -.07 & .02 & .05 & .02 & .04 & .01 & 0 \\
\hline 8 & .0015 & .07 & .03 & .09 & .02 & .01 & -.02 & .02 & .01 & .02 \\
\hline
\end{tabular}

Characteristics: $\mathrm{A}=$ dry weigh $(\mathrm{g}$.); $\mathrm{B}=$ length of the forewing; $\mathrm{C}=$ width of the forewing; $\mathrm{D}=$ length of the hindwing; $\mathrm{E}=$ width of the hindwing; $\mathrm{F}=$ total length of the antenna; $\mathrm{G}=$ length of the head; $\mathrm{H}=$ width of the head; $\mathrm{I}=$ length of the composed eye; $\mathbf{J}=$ width of the composed eye. Characteristics $B$ and $\mathbf{J}$ is represented in $\mathrm{mm}$.

TABLE 5

Indexes calculated for each characteristic and phenotypic index (W) of each colony.

\begin{tabular}{|c|c|c|c|c|c|c|c|c|c|c|c|}
\hline \multirow{2}{*}{ Col. N. } & \multicolumn{10}{|c|}{ Characteristics } & G \\
\cline { 2 - 13 } & A & B & C & D & E & F & G & H & I & J & W \\
\hline 1 & 8.62 & 5.56 & 7.69 & 7.41 & 11.76 & 22.86 & 12.50 & 13.16 & 6.25 & 30.78 & 12.66 \\
\hline 2 & 5.17 & 3.71 & 26.92 & 9.26 & 29.41 & 14.29 & 18.75 & 10.53 & 12.50 & 15.38 & 14.59 \\
\hline 3 & 5.17 & 18.52 & 30.77 & 20.37 & 23.53 & 20.00 & 21.87 & 2.63 & 18.75 & 0 & 16.16 \\
\hline 4 & 1.72 & 0 & 7.69 & 7.41 & 5.89 & 5.71 & 15.63 & 7.89 & 31.25 & 15.38 & 9.86 \\
\hline 5 & 22.42 & 33.33 & 0 & 24.07 & 5.89 & 11.43 & 12.50 & 10.53 & 18.75 & 15.38 & 15.43 \\
\hline 6 & 8.62 & 12.96 & 3.85 & 1.85 & 0 & 8.57 & 6.25 & 39.47 & 0 & 7.70 & 8.93 \\
\hline 7 & 22.42 & 12.96 & 11.54 & 12.96 & 11.76 & 14.29 & 6.25 & 10.53 & 6.25 & 0 & 10.90 \\
\hline 8 & 25.86 & 12.96 & 11.54 & 16.67 & 11.76 & 2.85 & 6.25 & 5.26 & 6.25 & 15.38 & 11.48 \\
\hline
\end{tabular}

Characteristics: $\mathrm{A}=$ dry weigh (g.); $\mathrm{B}=$ length of the forewing; $\mathrm{C}=$ width of the forewing; $\mathrm{D}=$ length of the hindwing; $\mathrm{E}=$ width of the hindwing; $F=$ total length of the antenna; $G=$ length of the head; $H=$ width of the head; $I=$ length of the composed eye; $\mathrm{J}=$ width of the composed eye.

TABLE 6

Correlation indexes between the analyzed morphologic characteristics and the areas with brood, honey and pollen $(\mathrm{N}=8)$.

\begin{tabular}{|c|c|c|c|c|c|c|c|c|c|c|c|c|c|c|}
\hline & $\mathbf{A}$ & $\mathbf{B}$ & $\mathbf{C}$ & $\mathbf{D}$ & $\mathbf{E}$ & $\mathbf{F}$ & $\mathbf{G}$ & $\mathbf{H}$ & $\mathbf{I}$ & $\mathbf{J}$ & $\mathbf{C R}$ & $\mathbf{M}$ & $\mathbf{P}$ & $\mathbf{G P}$ \\
\hline $\mathrm{B}$ & -.13 & -.31 & .68 & .16 & .41 & $\mathbf{. 8 2}$ & -.37 & -.35 & .49 & .45 & 1 & .57 & 69 & .44 \\
\hline $\mathrm{H}$ & -.06 & .54 & .59 & .77 & -.53 & .72 & -.18 & -.10 & .43 & .32 & .57 & 1 & .02 & 09 \\
\hline $\mathrm{P}$ & .15 & -.65 & .38 & .36 & -.04 & .31 & .36 & -.03 & -.02 & .57 & .69 & .02 & 1 & .59 \\
\hline
\end{tabular}

Characteristics: $\mathrm{A}=$ dry weigh; $\mathrm{B}=$ length of the forewing; $\mathrm{C}=$ width of the forewing; $\mathrm{D}=$ length of the hindwing; And = width of the hindwing; $\mathrm{F}=$ total length of the antenna; $\mathrm{G}=$ length of the head; $\mathrm{H}=$ width of the head; $\mathrm{I}=$ length of the composed eye; $\mathbf{J}=$ width of the composed eye; $\mathrm{B}=$ brood; $\mathrm{H}=$ honey; $\mathrm{P}=$ pollen. The correlations marked in boldface are significant for $\mathrm{p}<.05000$ 
TABLE 7

Correlation matrix among the analyzed morphologic characteristics $(\mathrm{N}=300)$.

\begin{tabular}{|c|c|c|c|c|c|c|c|c|c|c|}
\hline & $\mathbf{A}$ & B & C & D & $\mathbf{E}$ & $\mathbf{F}$ & $\mathbf{G}$ & $\mathbf{H}$ & I & $\mathbf{J}$ \\
\hline A & 1.00 & .08 & .19 & .09 & .13 & -.03 & .03 & .08 & -.09 & .04 \\
\hline B & & 1.00 & .39 & .55 & .21 & .08 & .21 & .19 & .19 & -.10 \\
\hline C & & & 1.00 & .34 & .42 & .18 & .12 & .09 & .18 & -.02 \\
\hline D & & & & 1.00 & .28 & .16 & .23 & .15 & .26 & -.06 \\
\hline E & & & & & 1.00 & .05 & .08 & .09 & .04 & -.01 \\
\hline $\mathrm{F}$ & & & & & & 1.00 & -.07 & -.01 & .13 & .01 \\
\hline G & & & & & & & 1.00 & .18 & .15 & -.05 \\
\hline $\mathrm{H}$ & & & & & & & & 1.00 & .06 & .10 \\
\hline I & & & & & & & & & 1.00 & .11 \\
\hline $\mathrm{J}$ & & & & & & & & & & 1.00 \\
\hline
\end{tabular}

Characteristics: $\mathrm{A}=$ dry weigh; $\mathrm{B}=$ length of the forewing; $\mathrm{C}=$ width of the forewing; $\mathrm{D}=$ length of the hindwing; And = width of the hindwing; $\mathrm{F}=$ total length of the antenna; $\mathrm{G}=$ length of the head; $\mathrm{H}=$ width of the head; $\mathrm{I}=$ length of the composed eye; $\mathbf{J}=$ width of the composed eye. The correlations marked in boldface are significant for $\mathrm{p}<.05000$.

With relationship to the morphologic characteristics, the model of normalizing selection was characterized for five of the analyzed morphologic characteristics, that is to say: width of the forewing and hindwing; length of the antenna, head and of the composed eye.

It is important to highlight that the total length of the antenna also presented positive correlation with the honey and of brood areas in the combs, what can indicate a peculiar importance of that character.

Jaqueline D. Oliveira and Ana Maria Bonetti for help in the field and laboratory studies.

\section{REFERENCES}

BRANDEBURGO, M. A. M. \& GONÇALVES, L. S., 1989, Environmental influence on the aggressive (defense) behaviour and colony development of Africanized bee (Apis mellifera). Ciência e Cultura, 42(10): 759-771.

BRANDEBURGO, M. A. M., 1995, As características morfológicas e a adaptabilidade das abelhas africanizadas (Apis mellifera). Revista do Centro de Ciências Biomédicas da UFU, 11(1): 37-42.

FUTUYMA, D. J., 1992, Biologia Evolutiva. Ed. Soc. Brasileira de Genética, Ribeirão Preto, SP, 631p.

EISCHEN, F. A., ROTHENBUHLER, W. C. \& KULINCEVIC, J. M., 1982, Length of life and dry weight of worker honeybees reared In colonies with different worker-larva ratios. Journal of Apicultural Research, 21: 19-25.
In gerenal, it can be concluded that phenotipically similar individuals, closer to the average in all morphological characters, were more adapted to the environment conditions. In that case, the morphologic characteristics presented by those individuals probably check them adaptive advantages, characterizing the medium phenotype presented by a population of a certain area.

Acknowledgments - This research was supported by a Federal University of Uberlândia, MG, and CNPq. We thank

KERR, W. E., 1967, The history of introduction of African Bees in Brazil. South Africa Bee Journal, 39: 3-5.

KOLMER, S. A. \& SAM, Y., 1991, Relationships between sizes of morphological features in worker honeybee (Apis mellifera). Journal of New York Entomology Society, 99(4): 684-690

MATTU, V. K. \& VERMA, L. R., 1983, Comparative morphometric studies on the Indian honeybee of the Northwest Himalayas 1. Tongue and Antenna. Journal of Apicultural Research, 22: 79-85.

MAYR, E., 1977, Populações, Espécies e Evolução. Companhia Editora Nacional, São Paulo, 485p.

MEIXNER, M., RUTTNER, F., KOENIGER, N. \& KOENIGER, G., 1989, The mountain bees of the Kilimanjaro region and their relation to neighboring bee populations. Apidologie, 20: 165-174.

METTLER, L. E. \& GREGG, T. G., 1973, Genética de Populações e Evolução. Polígono, São Paulo, 262p. 
MILNE, C. P. JR., 1981, Laboratory measurement of honey production in the honeybee 4 . Relationship between responses on tests of hoarding, longevity or length of life and pupa weight of the worker. Journal of Apicultural Research, 20(1): 28-30.

MILNE, C. P. JR. \& FRIARS, G. W., 1984, An estimate of the heritability of honeybee pupa weight. Journal of Apicultural Research, 75: 509-510.

MILNE, C. P. JR. \& PRIES, K. J., 1984, Honeybee corbicular size and honey production. Journal of Apicultural Research, 23: 11-14.

MILNE, C. P. JR., HELLMICH, R. L. \& PRIES, K. J., 1986, Corbicular size in workers from honeybee lines for high or low pollen hoarding. Journal of Apicultural Research, 25(1): 50-52.

PARDO, A. M., 1979, La abeja africanizada: aspectos sobre su origen, biologia y manejo. Conference de VI Congresso Colombiano de Entomologia, Cali, 40p.
PUTTKAMMER, E., 1994, Curso de Apicultura. Secretaria de Estado da Agricultura e Abastecimento. Empresa de Pesquisa Agropecuária e Difusão de Tecnologia de Santa Catarina S.A., 140p.

RINDERER, T. E., OLDROYD, B. P. \& SHEPPARD, W. S., 1993, Africanized Bee in the United States. Scientific American, 269(6): 52-58.

SINGH, M. P., 1990, Morphometric analysis of the Indian honeybee in the Northeast Himalayan region. Journal of Apicultural Research, 29(1): 3-14.

WADDINGTON, K. D., 1989, Implications of variation in worker body size for the honey bee recruitment system. Journal of Behavior, 2(1): 91-103.

WIESE, H., 1995, Novo manual de apicultura. R.S. Livraria e Editora Agropecuária LTDA. Guaíba, Rio Grande do Sul, 292p. 